\title{
DIE BESTUDERING VAN DIE NUWE TESTAMENT AS WESENLIKE ELEMENT VAN DIE VAK BYBELKUNDE
}

\section{H. J. B. COMBRINK}

1. Enkele inleidende opmerkings.

1.1. Dit is noodsaaklik om ten aanvang daarop te wys dat soos hierdie kongres as geheel - ook hierdie referaat besonder situasie- en tydgebonde van aard is. Op hierdie besondere tydstip, bepaal deur die ontwikkeling van Bybelkunde hier te lande tot op hede, is dit hopelik sinvol om die volgende gedagtes romdom die bestudering van die Nuwe Testament as wesenlike element van Bybelkunde in $u$ midde te lê.

1.2. Waarskynlik sal in ander referate voldoende aandag bestee word aan die noodsaaklikheid en die bestaansreg van Bybelkunde as vak. Hier word dus daarvan uitgegaan dat daar in ons dag ' $n$ steeds toenemende bewussyn is van die geweldige gaping tussen ons tyd en wêreld en dié van die Bybel. ${ }^{1}$ ) 'n Grondige vertroudheid met, maar veral ook ' $n$ juiste siening van die Bybel is dus van die grootste belang om die Bybel nie bloot formeel te ken nie, maar ook inderdaad deur die Bybel aangespreek te word. Hiertoe kan Bybelkunde en in hierdie geval die bestudering van die Nuwe Testament diensbaar wees.

1.3. Die feit dat die Bybel, as die Woord van God, hier die voorwerp van studie is, druk onteenseglik 'n bepaalde stempel op dié vak af. Ofskoon Bybelkunde hier te lande meestal in die Fakulteit Lettere en Wysbegeerte aangebied word, benadruk I. H. Eybers tereg dat dit basies 'n teologiese dissipline is. ${ }^{2}$ )

Dit is m.i. iets waarvoor ' $n$ mens alleen maar dankbaar kan wees dat in dergelike gekonsentreerde bestudering van die Bybel ook buite 'n volledige Teologiese kurrikulum moontlik is.

2. Die besondere plek van die bestudering van die Nuwe Testament in Bybelkunde.

2.1. Hoewel dit duidelik is dat Bybelkunde in die buiteland nie noodwendig altyd dieselfde opset het as by ons nie, kan tog beweer word dat dit basies die bestudering van die Ou en Nuwe Testament behels. ${ }^{3}$ ) Maar afgesien hiervan 
dui die naam van die vak as sodanig reeds ' $n$ besondere konsentrasie op die Bybel self aan. Waar dit nou daarom gaan dat vir veral - maar nie alleen - voornemende onderwysers die Bybel ontsluit") sal word, waar die studie gerig is op die verstaan van die Bybel as sodanig, moet die $\mathrm{Ou}$ en Nuwe Testament die belangrikste komponente wees. Hier is die ou Reformatoriese stelreël sacra scriptura sui ipsius interpres dus werklik ter sake. In die lig van wat hierbo (1.3) reeds gesê is oor die Teologiese aard van Bybelkunde, impliseer dit dus dat veral die sogenaamde Bibliologiese vakke hier op een of ander wyse ter sprake kom. Dit sluit egter nie uit dat daar 'n behoefte bestaan aan die behandeling van sekere hooflyne soos skepping, sonde, genade en verlossing wat deur beide Testamente heen gevolg sal moet word nie.")

2.2. Tussen Godsdiensonderrig en Bybelkunde word normaalweg so onderskei dat Godsdiensonderrig 'n wyer terrein dek as Bybelkunde. ${ }^{6}$ ) Nou is dit besonder interessant dat in die diskussie rondom kategese en godsdiensonderrig in Duitsland, daar in die laaste jare hernieude aandag gevra is vir die wesensbepaling van die "Religionsunterricht" op skool, naamlik dat dit basies om die uitleg en die vertolking van die teks van die Bybel gaan. Ofskoon dit streng gesproke vir ons sieningè van Bybelkunde nie ter sake is nie, is dit tog in ' $n$ sekere sin besonder interessant dat juis in die "wyer" Godsdiensonderrig en Kategese daar so ' $n$ duidelike terugkeer na die Bybel self is. ${ }^{7}$ )

2.3. Wanneer nou aanvaar word dat Bybelkunde basies die bestudering van die Ou Testament en die Nuwe Testament behels, vloei daaruit verder voort dat albei hierdie komponente 'n gelykwaardige gewig behoort te dra, vir 'n groot deel van die kursus altans. 'n Mens sou egter kon vra wanneer spesialisasie gewens word - dit wil sê moet 'n Hons.-kursus reeds alleen op óf die O.T. óf die N.T. toegespits wees, of behoort ook nog op hierdie vlak albei komponente eweveel gewig te dra.

Al word die eerste drie jare in Bybelkunde ook so intensief as moontlik aangepak, lyk dit tog nie raadsaam om alreeds op Hons.-vlak alleen op die O.T. of N.T. te spesialiseer nie. Hier behoort die N.T. en O.T. gelyke gewig te dra, terwyl veral op hierdie vlak ook besondere aandag aan die eenheid van die O.T. en die N.T. en die hooflyne van die Bybel se boodskap gegee dien te word. 
2.4. Op M.A.-vlak is spesıalisasie in die O.T. of N.T. voor die hand liggend, voortbouend op die basis wat in die Hons.reeds gelê is.

2.5. Die studie van die Nuwe Testament op doktorale vlak sal altyd óf hoofvak, òf 'n byvak saam met O.T. as hoofvak moet wees. Oor die tweede byvak loop die meninge waarskynlik uiteen - maar dit is streng gesproke nie hier direk ter sprake nie. 'n Proefskrif sou derhalwe ook òf oor 'n Nuwe-Testamentiese òf 'n Ou-Testamentiese onderwerp kan handel.

2.6. In hierdie verband moet die vraag egter geopper word of die bestudering van die Nuwe Testament, wat so 'n belangrike plek inneem in Bybelkunde, dan alleen met behulp van vertalinge geskied, en of daar enige vereistes ten opsigte van die kennis van Grieks gestel word.

2.6.1. In die praktyk is die brandende vraag hier waarskynlik of daar reeds dergelike voorvereistes in die B.A.-jare gestel kan word. Soos bekend, vereis enkele van ons universiteite ${ }^{*}$ ) Grieks I (of Hebr. I) as voorvereiste vir Bybelkunde III. Oor die intrinsieke waarde van so 'n vereiste sal daar waarskynlik nie veel verskil van mening wees nie. Die nuwe wêreld wat oopgaan o.g.v. studie van minstens één van die grondtale, die vermeerderde insig in Bybelse begrippe asook die vrugbaarder gebruikmaking van populêre en meer gevorderde kommentare spreek vanself. Dat sulke studente die onderwysprofessie alleen maar grootliks kan verryk, is sonder meer duidelik.

Tog is daar ook probleme hieraan verbonde. In die praktyk is dit tog so dat die tale - ten regte of ten onregte - in groot aantal studente van Bybelkunde III weghou. Hoewel die praktyk seker nie aan die Universiteit kan voorskryf nie, bestaan die vak aan die Universiteit ook weer nie los van die praktyk nie. Dit word dan 'n dringende vraag of die doel bereik word deur 'n relatief klein aantal kandidate op 'n besondere wyse met Bybelkunde III toe te rus, en of ' $n$ mens nie juis aan die doel verbyskiet deur so 'n redelike groot aantal mense met slegs Bybelkunde II (wat graag Bybelkunde III sou wou geneem het) die onderwys in te stuur - in feite dus minder goed toegerus as wat hulle kon gewees het. Oor die toerusting van 'n student 
wat oor Bybelkunde III met inbegrip van een van van die grondtale beskik, bestaan geen twyfel nie. Die keersy van die saak is egter ook duidelik Bybelkunde III sonder ' $n$ grondtaal is hopelik 'n vollediger toerusting as Bybelkunde II sonder ' $n$ grondtaal, met die weg na die derde jaar afgeslote weens die voorvereiste. Die besonder belangrike plek van die Nuwe Testament in die opset van Bybelkunde maak groter eenstemmigheid oor hierdie saak gewens.

2.6.2. Oor die noodsaak van Grieks I as vereiste vir die bestudering van die Nuwe Testament op Hons.vlak, is die eenstemmigheid hopelik redelik algemeen. Hier gaan die weë miskien uiteen ten opsigte van die aard van die voorvereiste: ' $n$ formele vereiste voor die aflegging van die eksamen, of 'n vereiste voor die effektiewe bestudering van die Nuwe Testament gedurende die kursus self.

2.6.3. Wanneer 'n M.A.-verhandeling oor 'n Nuwe-Testamentiese onderwerp handel, sou Grieks II as vereiste, seker as 'n realistiese eis aanvaar word.

2.6.4. Dieselfde sou geld vir die bestudering van die N.T. op doktorale vlak, hetsy as hoofvak (wanneer Grieks III verwelkom sou word), hetsy as byvak. Waar daar nog redelikerwyse met die eise van die praktyk rekening gehou kan word ten opsigte van die taalvereiste op die vlak van Bybelkunde III, lyk dit nie akademies verantwoord om op nagraadse vlak verdere toegewings in hierdie verband te maak nie.

\section{Wat behels die bestudering van die Nuwe Testament?}

3.1. Vooraf moet eers in hierdie verband ' $n$ bepaalde standpuntbepaling verduidelik word. Daar moet naamlik rekening gehou word met die situasie soos dit reeds hier te lande gestalte aangeneem het dat alle inrigtings wat Bybelkunde doseer tans ook in beginsel Bybelkunde tot op doktorale vlak aanbied. Dit het sekere implikasies ook vir die B.A.-jare. Waar iemand soos Westermann sy Bybelkunde as ,nur die ersten Schritte in die Bibel hinein" kan karakteriseer, verklaar hy ook pertinent: „Wächst die Vertrautheit mit ihr (die Bybel) und die Freude an eigener Weiterarbeit, kann die Bibelkunde zurücktreten." 9 ) By ons is Bybelkunde nie maar net ' $n$ vak wat alleen maar wil 
inlei en oriënteer nie, maar sonder twyfel n vak wat die Bybel wil ontsluit so ver as dit ook maar moontlik is; 'n vak wat nie terugstaan sodat sy taak deur 'n ander vak oorgeneem moet word nie. Bybelkunde wil dus nie bloot ' $n$ inleidende taak verrig nie, maar wil so veel as moontlik van die Nuwe Testament en die relevante agtergrondmateriaal bestudeer as wat haalbaar en akademies verantwoord is.

In die verbygaan kan verwys word na die invloed van die vereistes van Bybelkunde as skoolvak op die aanbieding van Bybelkunde op universiteit. Sonder twyfel moet daar tot op 'n sekere hoogte rekening gehou word met die eise van die skoolleerplanne. Tog bepaal die universiteit selfstandig wat ter sprake gebring moet word ten einde die student so deeglik as moontlik toe te rus om die Nuwe Testament te kan verstaan en met behulp van 'n breë en omvattende vorming die skool se leerplan met gemak te kan implementeer.

3.2. Wanneer dan gevra word wat alles ter sprake kom in die Nuwe-Testamentiese gedeelte van Bybelkunde, verklaar Eybers tereg dat dit in hoofsaak dieselfde is as dit wat in die Nuwe-Testamentiese wetenskap aan die orde kom. ${ }^{10}$ )

3.2.1. Vir 'n juiste perspektief op die wêreld waarin die N.T. ontstaan het, is ' $n$ grondige inleiding in die breë terrein van die kultuur-historiese agtergrond van die Nuwe Testament van groot belang. ${ }^{11}$ ) Dink hier maar aan momente soos die Makkabeër-stryd, die begin van die spanning tussen Fariseërs en Sadduseërs, Jode en Samaritane, die omstandig. hede waaronder die sekte van Qumran hulle aan die volk onttrek, die regeringstyd van Herodes die Grote ens. Die noodsaaklikheid van gekonsentreerde aandag op die tussen-testamentêre tydvak kan moeilik te veel beklemtoon word. Dit bly egter steeds noodsaaklik om steeds nadruklik die waarde en $\sin$ van hierdie werk t.o.v. die verstaan van die Nuwe Testament aan te dui. Dit gaan om die volheid van die tyd (Gal. 4:4) toe die Woord waarlik vlees geword het (Joh. 1:1). Hoewel die oudheidkunde, argeologie, en aardrykskunde dikwels vanuit die Ou Testament behandel word, spreek dit vanself dat vir die verstaan van die N.T. ook hierdie sake onontbeerlik is. Waar nodig moet in elk geval aan spesifieke aspekte wat die N.T. raak, bykomende aandag bestee word. 
3.2.2. Die wyse waarop die teks van die Nuwe Testament vermenigvuldig en oorgelewer is, behoort ook pertinent aan die orde te kom. Dit sou m.i. moeilik te verskoon wees as iemand Bybelkunde geneem het, en byvoorbeeld nie kan verklaar waarom die nuwe Afrikaanse Bybelvertaling in sommige gevalle in die Nuwe Testament ' $n$ ander tekslesing het as die huidige teks nie. Die kennis van verskillende tipe skryfmateriale en lettertipes, tipe skryffoute, wyse van vermenigvuldiging van manuskripte, asook van die ontstaan en die omverwerping van die Textus Receptus is dus geen oortollige goeie werke nie. In aansluiting hierby sou die interessante veld van Bybselvertaling ook aangesny kan word. Hier is nie alleen die ou vertalings van die Nuwe Testament van belang en ter sake nie, maar ook die geskiedenis van die moderne vertalings met spesifieke verwysing ook na die nuwe benadering by die vertaling van die Nuwe Testament. Veral waar ons geslag bevoorreg is om die vrystelling van ' $n$ nuwe vertaling te beleef, is ' $n$ grondige agtergrond in hierdie verband onontbeerlik.

3.2.3. Ewe belangrik is dit om helderheid te bring rondom wat kanonies en apokrief is. Dit is ook sinvol om aan die historiese proses van erkenning van al die afsonderlike boeke aandag te gee. Rondom hierdie sake kom vrae aan die orde wat eenvoudig nie ontwyk kan word nie. Hoewel kennismaking met veral die Ou-Testamentiese Apokriewe so belangrik is vir die agtergrond van die Nuwe Testament, is dit tog ook sinvol om die Nuwe-Testamentiese Apokriewe, met hulle andersoortige belang, aan die orde te stel.

3.2.4. 'n Interessante saak waaroor daar waarskynlik verskil van mening sal wees, is die vraag in hoeverre die besondere Kanoniek of Inleidingsuraagstukke in Bybelkunde ter sprake moet kom. Aan die een kant kan die standpunt gehuldig word dat die Inleiding wel ter sprake kan kom, maar dan op 'n onopsigtelike wyse en sonder om self op die voorgrond te tree. ${ }^{22}$ ) Word dit egter aanvaar dat wat hier aan die orde kom werklik van belang is vir die verstaan van die teks self, terwyl dit juis gegrond is op die gegewens van die teks ${ }^{13}$ ), lyk dit 
my dat waar daar voldoende geleentheid vir diepgang in Bybelkunde is, hierdie sake aan die orde behoort te kom. ${ }^{14}$ )

Dit sal egter steeds nodig wees om pertinent verbande te lê en te benadruk waarom die bestudering van dergelike sake van belang is vir die verstaan van die Nuwe Testamentiese geskrifte. Hier geld miskien meer as by enige ander gedeelte van die stof wat aan die orde kom, dat die diepgang sal saamhang met die vlak van die studie.

3.2.5. 'n Aspek wat besondere nadruk behoort te ontvang, waartoe alles wat reeds genoem is in ' $n$ sekere mate alleen ",hulpdiens" gelewer het, is die uitlig en aantoon van die boodskap of die verkondiging van die Nuwe Testament as geheel, maar ook van die afsonderlike geskrifte van die Nuwe Testament.

Hier gaan dit dus om die Openbaringsgeskiedenis. ${ }^{13}$ ) In die Nuwe Testament hoor ons die Woord van God en openbaar God Homself aan ons Hierdie openbaring vertoon ' $n$ sekere voortgang en geskiedenis. Daarom is dit sinvol dat die boodskap van die Ou Testament afsonderlik bestudeer sal word en so ook dié van die Nuwe Testament - ofskoon 'n samevatting en geheeloorsig ook op 'n gegewe oomblik noodsaaklik is. Die openbaringsgeskiedenis kan histories of tematies benader word.

Die tematiese aanpak kan sonder twyfel baie waardevol wees. veral ten opsigte van bepaalde gedeeltes van die Nuwe Testament. Tog kom dit dan ter sprake binne ' $n$ basiese historiese raamwerk wat eintlik die sinvolste uitgangspunt bied. Ander verkies om die boodskap van die Nuwe Testament as geheel so tematies aan te bied. ${ }^{15}$ ) By die Evangelies kan die historiese aanpak op verskillende wyse benader word. Sonder dat daar gepoog word om 'n lewensbeskrywing van Jesus te gee, kan op grond van die gegewens van al vier die Evangelies die gang van die Openbaringsgeskiedenis aangedui word deur aandag te vra vir bepaalde momente wat Openbaringshistories van groot waarde is. ${ }^{1-}$ ) 'n Ander moontlikheid is egter om elke Evangelie afsonderlik te ondersoek en te 
probeer vasstel watter besondere aksent of reliëf die verkondiging van Christus in elkeen afsonderlik kry. ${ }^{1 *}$ ) 'n Mens sou liewers altwee benaderings aanvullend tot mekaar moes gebruik - maar tog sou ek persoonlik die voorkeur daaraan gee om eers die afsonderlike geskrifte volledig ,aan te hoor" voordat daar verder gesistematiseer word. Dieselfde geld ook vir die briewe van Paulus. Sy verkondiging kan besonder sinvol aan die hand van bepaalde temas uiteengesit word - tog mag die besondere reliëf van sy afsonderlike briewe nie verwaarloos word.

Wanneer ten volle reg gedoen is aan die veelkleurige verskeidenheid van die Nuwe Testament, moet die eenheid van die boodskap van die Nuwe Testament ook aangedui word, want hierom gaan dit - dat Bybelkunde die Nuwe Testament werklik tot spreke moet bring.

3.2.6. Die uitleg of verklaring van bepaalde Skrifgedeeltes behoort ook ter sprake te kom. Die wyse waarop dit sal geskied hang uiteraard ten nouste saam met die taalvereistes wat in 2.6 ter sprake was. Dit is ook duidelik dat die verklaring in Bybelkunde nie op dieselfde wyse as in die Teologiese Fakulteit kan geskied nie. Tog neem dit nie weg nie dat met behulp van die vele hulpmiddels vandag beskikbaar, 'n Bybelkundestudent (ook een wat geen Grieks of Hebreeus ken nie) tog met die verloop van sy studiejare steeds weer hiermee gekonfronteer behoort te word. Trouens, is dit nie 'n toetssteen vir die kursus as geheel, dat hy inderdaad die Bybel met meer begrip en insig sal kan lees nie? Dit spreek egter vanself dat veral op nagraadse vlak steeds grondiger hierop ingegaan sal word.

3.2.7. In hierdie verband dring nog 'n studieveld onvermydelik na vore, naamlik die behoefte aan leiding ten opsigte van die basiese beginsels vir die verklaring van die Bybel. Juis diegene wat geen volledige Teologiese kursus deurloop nie, het ' $n$ besondere behoefte hieraan. Dit geld natuurlik die Bybel as geheel (bv. allegorie, tipologie, ens.) ook, maar dit is noodsaaklik om ook wat die Nuwe Testament betref duidelike riglyne aan te dui vir die uitleg van gelykenisse, apokoliptiese stof, ens. 
Veral wanneer die geleenthede en verantwoordelikhede van die Bybelkunde-onderwyser op skool in gedagte gehou word, kan die belang van hierdie saak nie genoeg benadruk word nie. Die interessante vraag is egter op watter stadium van die kursus so iets ter sprake behoort te kom. Dit sou besonder sinvol in Bybelkunde III behandel kon word, maar dan kom 'n groot aantal studente nie daarmee in aanraking nie.

\section{Enkele metodologiese opmerkings.}

$\mathrm{Na}$ aangedui is wat in die bestudering van die Nuwe Testament ter sprake behoort te kom, sou vervolgens aangedui kon word wat op watter stadium ter sprake moes kom. Is daar ' $n$ moontlikheid om tot eenstemmigheid te geraak in verband met 'n leerplan? $\mathrm{Na}$ alle waarskynlikheid is hier 'n groot aantal benaderingswyses moontlik.

4.1. Een moontlike benadering kan wees om in Bybelkunde Imet die oog op die groot aantal studente wat alleen die één kursus volg - op 'n oorsigtelike wyse soveel as moontlik van die Nuwe Testament as geheel ter sprake te bring. Op hierdie wyse word getrag om selfs net die een kursus so sinvol as moontlik te laat funksioneer met die oog op ' $n$ beter insig in en begrip van die Bybel. In die verdere kursusse sal dan uiteraard teruggekom moet word op belangrike momente, maar dan meer in besonderhede. ${ }^{19}$ )

4.2. Vir so ' $n$ benadering is besonder veel te sê. Tog is daar ook ' $n$ ander benadering moontlik, waarby daar weliswaar ook sekere inleidende aangeleenthede in die eerste kursus aan die orde kom. maar waar sekere belangrike momente vervolgens onmiddellik aan die orde kom op so ' $n$ wyse dat alles wat onder punt 3 genoem is, op een of ander tyd in die drie B.A.-jare ter sprake kom. Hierby sou natuurlik steeds die jaarvlak waarop 'n saak aan die orde kom, deeglik in berekening gebring moet word. Die vraag bly steeds: wat moet in so 'n opset eerste aan die orde gestel word.

In so 'n opset sou 'n mens in kursus I heelwat van die historiese, kulturele en ander agtergrondsmateriaal soos die Teks en kanon aan die orde kon stel. Dit hou onder andere die voordeel in dat dit oor die algemeen heeltemal of redelik onbekende stof is wat die student se belangstelling besonder sterk prikkel, terwyl dit die belangrike 
maar onbekende tussentestamentêre tydperk belıg. ${ }^{20}$ ) Tog moet daar sonder twyfel in die eerste jaar ook genoegsaam met die Nuwe Testament self - en nie alleen agtergrondsmateriaal nie - kennis gemaak word. Die vraag is nou egter waar begin moet word. Daar kan vier moontlike benaderings onderskei word."')

Eerstens kan die volgorde van die boeke van die Nuwe Testament gevolg word. Hierdie benadering lewer beslis sekere probleme op, soos o.a. dat die Sinoptiese vraagstuk dan reeds in Bybelkunde I ter sprake kom. 'n Tweede moontlikheid is om kronologies te werk te gaan en derhalwe met die vroegste briewe van Paulus te begin. Tog kan so ook 'n skewe beeld ontstaan asof Paulus se arbeid eintlik basies was - terwyl die optrede van Jesus tog daarvan ten grondslag gelê het.

Derdens sou mens kon uitgaan van die optrede van Jesus soos dit uit die Evangelies gerekonstrueer kan word en dan voortgaan tot die laaste boek wat van Hom getuig. Price kies 'n vierde moontlikheid waarvolgens hy begin met die eerste gedeelte van Handelinge (1-12) wat die lotgevalle van die vroeë Christene behandel. Hierdie periode laat ' $n$ lig val op die ontstaangeskiedenis van die Sinoptiese evangelies wat dan vervolgens aan die orde kom. Daarna volg 'n rekonstruksie van Jesus se bediening. Vervolgens word aandag bestee aan die laaste gedeelte van Handelinge (13-28) om daarna Paulus se briewe en dan die res van die geskrifte in hulle waarskynlike kronologiese orde te behandel.

Ten spyte van die probleme daaraan verbonde kan dit sinvol wees om tog maar dadelik met die Sinoptiese evangelies te begin. ' $n$ Inleiding in die ontstaansgeskiedenis en besondere boodskap van die Sinoptiese evangelies is tegelyk besonder insiggewend met betrekking tot die konsekwensies van die organiese inspirasieleer. Vanselsprekend kom ook die boodskap van hierdie evangelies pertinent aan die orde met besondere verwysing na belangrike openbarings-historiese momente in die optrede van Jesus. Sonder om nou onnodig op besonderhede in te gaan, kan in 'n volgende kursus op Handelinge en Paulus se briewe ingegaan word en vervolgens op die Johanneiese geskrifte en ander briewe.

4.3. Metadologies gesien, is dit besonder belangrik om te benadruk dat die Bybel self werklik in die sentrum van die studie moet staan. In hierdie verband kan verwys 
word na twee redelik onlangse publikasies wat elk op sy eie manier werklik die Nuwe Testament self aan die woord laat kom.

In Anatomy of the New Testament word besonder grondig ingegaan op bepaalde belangrike perikope uit die geskrifte van die Nuwe Testament. .Working outward from these texts, we have then endeavoured to display and illumine the character and movement of the different writings. What has resulted in certainly no comprehensive or even coverage of the New Testament, but a series of dissections or biopsies designed to uncover the nature and structure of the New Testament books out of the collection as a whole." ${ }^{-2}$ ) Ofskoon ons waarskynlik tog nie hiermee kan volstaan nie, is dit 'n besonder waardevolle boek wat die leser werklik terugbring na die teks van die Nuwe Testament.

'n Enigsins ander benadering vind ons in Introduction to the New Testament van D. J. Selby. Hy wyk af van die stereotipe benadering deur ook breedvoerige aandag te gee aan die uiteensetting van die Nuwe Testamentiese geskrifte self. Sy benadering is in ooreenstemming met die „,program of composition criticism" ${ }^{\prime 2}$ ) aangesien ook hy die leser wil help om die Nuwe Testament, soos hy dit voor hom het, beter te verstaan. Selby gaan in elk geval deeglik op sekere inleidingsvraagstukke in.

Die laaste woord is in hierdie verband sekerlik nog nie gespreek nie. Belangrike faktore sal hier sonder twyfel die jaarvlak van die studente wees, asook die leerskool van die ondervinding op voorgraadse vlak.

5. Die betekenis van die bestudering van dis Nuwe Testament in Bybelkunde.

Indien die bestudering van die Nuwe Testament as onderdeel van Bybelkunde meehelp tot in suiwerder benadering van en 'n dieper insig in die Nuwe Testament en die Bybel as geheel, dan was die "baie boeke maak en baie studie" darem nie alles tevergeefs nie. Om dit te bereik sal die sinvolheid en die waarde van die verskillende onderafdelings telkens aangedui moet word.

Ten diepste gaan dit dus daarom dat die boodskap, die verkondiging van die Nuwe Testament duidelik sal word, en dit beteken dat die stem van die lewende Here gehoor sal word. Ofskoon die Nuwe Testament vanselfsprekend nou in ' $n$ ander situasie ter sprake kom as wanneer dit in die boesem van die 
gemeente gebeur, neem dit nie weg dat ook Bybelkunde tot taak het om die Nuwe Testament te vertolk en uit te lê nie. Besonder duidelik stel Frör dit: „Das gilt auch für die unterweisende Auslegung in der Schule und für jede andere hermeneutische Bemühung, die nicht im Gottesdienst selbst, sondern in den verschiedenen Lebensformen der Gemeinde geschieht. Die theologische Schriftauslegung kann hier um keinen Preis zweigleisig arbeiten, indem sie zwei Verfahren nebeneinander stellt, von denen das eine in die Predigt und das andere in den Unterricht, das eine in die Kirche und das andere in die Schule gehört."'2t)

Werk Bybelkunde daartoe mee dat die Nuwe Testament inderdaad na sy eie bedoeling verstaan word, dan word ons Protestantse erfenis gedien. Dit moet dan as 'n geweldige winspunt gesien word dat die Nuwe Testament teruggeplaas kan word in die hand van mense wat nie volbloed teoloë is nie, maar wat as lede van die kerk van Christus steeds meer en meer die vreugde kan smaak om as iemand wat in leerling geword in die koninkryk van die hemele... uit die skat van die Woord van God nuwe en ou dinge te voorskyn te bring. (Matt. 13:52.)

\section{AANTEKENINGE}

1) Vgl. C. Westermann, Abriss der Bibelkunde. Altes und Neues Testament, Stuttgart-Gelnhausen, 1962, 8.

2) I. H. Eybers, Bybelkunde, in: Inleiding in die Teologie (onder redaksie van I. H. Eybers, A. Köning, J. A. Stoop), Pretoria 1973, 29 v.

3) Vgl. C. Westermann, a.w.: O. Weber, Grundriss der Bibelkunde, Göttingen, 1949; H. Gross, Kleine Bibelkunde zum Alten Testament, München 1966; P. Neuenzeit, Kleine Bibelkunde zum Neuen Testament, München 1967; O. Weber, Bibelkunde des Alten Testaments, Hamburg 1961; W. Brandt, Neutestamentliche Bibelkunde. Eine Einführung in Inhalt und Gestalt der urchristlichen Botschaft, Gladbeck 81966; K. Gutbrod, Kurze Bibelkunde des Neuen Testaments, Stuttgart 1973.

4) Vgl. vir die begrip ontsluiting J. C. Lombard, Die Betekenis van Bybelkunde as akademiese dissipline. (Intreerede gelewer op 1 Maart 1973 aan die Universiteit van die Oranje-Vrystaat), Bloemfontein 1973, 8.

5) Vgl. C. Westermann, Abriss, $9 v$.

6) I. H. Eybers, a.a., 28v.

7) Sien hiervoor W. Langer, The Development of the Bible Lesson in German Catechetics, Concilium 6/3 (1970), 116-127; A. Barth, Die Bibel im Religionsunterricht, Donauwörth 1973, 16v; K. Frör, Der Religionsunterricht an den öffentlichen Schulen als unbewältigtes theologisches Problem, Schule und Leben 1963, 300, 292: ,führt das notwendig zur Interpretation biblischer Texte in einem eigenen Fach der heutigen Schule."

8) Bv. RAU en Rhodes. Dit is interessant dat by die Universiteit van St. Andrews Grieks I of Hebreeus I vereis word van diegene wat ' $n$ tweedejaar-kursus in "Biblical Studies" neem met die oog op die onderwys.

9) C. Westermann, a.w.: 10.

10) I. H. Eybers, a.a., 33. 
11) Vgl. W. Langer, a.a., 120: .,The ultimate object of such lessons is an understanding of the New Testament in the light of the historical period in which it came into being ..." Vgl. ook E. Lohse, Umwelt des Neuen Testaments, Göttingen 1971, 5v.

12) Vgl. C. Westermann, a.w., 9. So ook W. Brandt, Neutestamentliche Bibelkunde en $O$. Weber, Grundriss.

13) Vgl. I. H. Eybers, Die Ou-Testamentiese Wetenskap, Inleiding in die Teologie, 42; F. J. Botha, Die Nuwe-Testamentiese Wetenskap, Inleiding in die Teologie, 76v; G. Eichholz, Neues Testament, Einführung in das Stadium der evangelischen Theologie (R. Bohren e.a.). München 1964, 93v.

14) W. Langer, a.a., 120, verwys o.a. na $H$. Halbfas wat voorgestel het dat ook die Sinoptiese vraagstuk nie ontwyk moet word nie - hier gaan dit om die vak op skoolvlak.

15) Vgl. hiervoor Tjaart van der Walt, Openbaringsgeskiedenis van die Nuwe Testament - 'n Gids vir Bybelkunde studente, Deel A: Agtergrond (vir private gebruik alleen). Potchefstroom 1973, 1vv. Sien ook F. J. Botha, a.a., 81vv.

16) Vgl. J. H. E. Hull, The Message of the New Testament (Understanding the Bible 6), Oxford 1971.

17) So bv. T, van der Walt, a.w. Deel B: Die Messias op aarde (vir private gebruik alleen), Potchefstroom 1973. Vgl. ook A. M. Hunter, Introducing New Testament Theology, London 1957, 13-61.

18) Vgl. bv. F. F. Bruce. The Message of the New Testament, Exeter, 1972.

19) So bv. aan die Universiteit van St. Andrews.

20) Vgl. die intensiewe aandag vir die agtergrondsmateriaal in $\mathrm{H}$. A. Mertens, Handbuch der Bibelkunde Literarische, historische, archäologische, religionsgeschichtliche, kulturkundliche, geographische Aspekte der Heiligen Schrift des Alten und Neuen Testamentes geboten für Unterricht und Predigt, Düsseldorf 1966.

21) Vgl. J. L. Price, Interpreting the New Testament, Holt, Rinehart and Winston 21971, 18v.

22) R. A. Spivey, D. M. Smith, Jr., Anatomy of the New Testament. A Guide to its Structure and Meaning, London 1969, v., vi. Vgl. ook die interessante apmerking op p.vii: .The authors thus betray their own belief that the subject matter of the New Testament does not lie beyond the grasp of the lay reader."

23) D. J. Selby, Introduction to the New Testament. .,The Word become Flesh", New York 1971, vii.

24) K. Frör, Biblische Hermeneutik, Zur Schiftauslegung in Predigt und Unterricht. München 31967, 15. Vgl. ook Frör, a.a., 299, waar hy benadruk dat alle uitleg van die Skrif tegelyk verkondiging is. So ook $W$. Langer, a.a., 123: ,.In short, the true object even of classroom work on the Bible is interpretation." 